\title{
TRADE-OFFS IN DAPHNIA HABITAT SELECTION
}

\author{
Monika Winder, ${ }^{1,2,4}$ Piet SpaAk, ${ }^{1}$ And Wolf M. MooiJ ${ }^{3}$ \\ ${ }^{1}$ Department of Limnology, Eidgenössische Anstalt für Wasserversorgung Abwasserreinigung und Gewässerschutz \\ (EAWAG), Überlandstrasse 133, CH-8600 Dübendorf, Switzerland \\ ${ }^{2}$ Max-Planck-Institut für Limnologie, Abteilung Ökophysiologie, Postfach 165, 24302 Plön, Germany \\ ${ }^{3}$ Netherlands Institute of Ecology, Centre for Limnology, Rijksstraatweg 6, 3631 AC Nieuwersluis, The Netherlands
}

Abstract. Diel vertical migration (DVM) is a dynamic behavioral pattern found extensively in the world's oceans and lakes, yet the role of food and temperature distribution on DVM is still unclear. While DVM has been mostly studied in systems with surface food maxima, deep-water food maxima are quite common in lakes and oceans. In such ecosystems, optimal conditions of temperature and food are uncoupled. In a Swiss high-mountain lake (Oberer Arosasee) with a deep-water food maximum, we found that Daphnia galeata adults and juveniles exhibit DVM behavior almost throughout the year and migrated upwards, out of food-rich environments, at night. In a large indoor mesocosm experiment, we were able to show that Daphnia respond to fish-mediated cues by migrating into deeper water layers. In the presence of fish and using natural vertical food and temperature distributions in the mesocosms, we could reproduce the vertical distribution of adult Daphnia observed in the field. The indoor experiments show that food and temperature modulate the actual depth at which the animals stop migrating, whereas fish and ultraviolet radiation likely determine the timing of migration (its synchronization with dawn and dusk). Overall, our results show that the nighttime movement into the surface waters contributes to the fitness of Daphnia, given the costs and benefits associated with the trade-off between food and temperature.

Key words: deep-water chlorophyll maximum; diel vertical migration; enclosure experiment; fish kairomones; fish stocking; food-temperature trade-off; high-mountain lakes; phototaxis; plankton towers; zooplankton.

\section{INTRODUCTION}

Living in the open-water zone of lakes and oceans, where mortality risks show high temporal and spatial variability, animals are challenged to distribute themselves optimally over safe and risky habitats. According to a number of studies, the risk of predation primarily controls diel vertical migration (DVM) of various zooplankton species (Lampert 1993). It has been shown, however, that DVM is also influenced by food availability in the different water layers (Dini and Carpenter 1992), and by the vertical temperature distribution (Loose and Dawidowicz 1994). Food and temperature are important factors in determining growth (fitness) of filter feeders like Daphnia, because higher food availability increases clutch size (Lampert 1978) and higher temperature increases developmental rates (Bottrell et al. 1976). The axiom of the mortality-avoidance hypothesis is that the costs of residence at depth in terms of reduced feeding opportunities and decreased temperature may be quite high (Lampert 1993). In stratified lakes, surface waters are always warmer (except under ice cover), and the vertical gradient of

Manuscript received 28 July 2003; revised 25 November 2003; accepted 2 December 2003. Corresponding Editor: J. E. Havel.

${ }^{4}$ Present address: School of Aquatic and Fishery Sciences, University of Washington, Box 355020, Seattle, Washington 98195-5020 USA. E-mail: mwinder@u.washington.edu food availability may change considerably. It has become increasingly clear that food availability may not always be highest in surface waters as deep-water food maxima are well documented in various lakes and in the oceans (Fee 1976, Cullen 1982, Williamson et al. 1996, Winder et al. 2003a). Under these circumstances, optimal food and temperature levels are spatially uncoupled and migrating individuals are faced with a trade-off between rapid development but low energy input in surface waters and slow development but high energy input in deep layers.

In lakes with high food concentrations in deep waters and high predation pressure in the surface waters, Gliwicz and Pijanowska (1988) showed that Daphnia did not migrate, but remained in deep waters day and night. These authors hypothesized that upward migration should only occur if feeding conditions are better in the upper water layers. In addition, Vos et al. (2002) suggest that staying deep in the water column all day may be a more effective strategy at times of high predation pressure, even when food availability is higher in the risky surface habitat. In contrast, other field studies showed that zooplankters return to shallower waters at night, even when chlorophyll concentrations were higher in deep-water layers (e.g., Williamson et al. 1996, Winder et al. 2003a). If temperature is the most important factor, as suggested by Loose and Dawidowicz (1994), upward migration might optimize fitness 


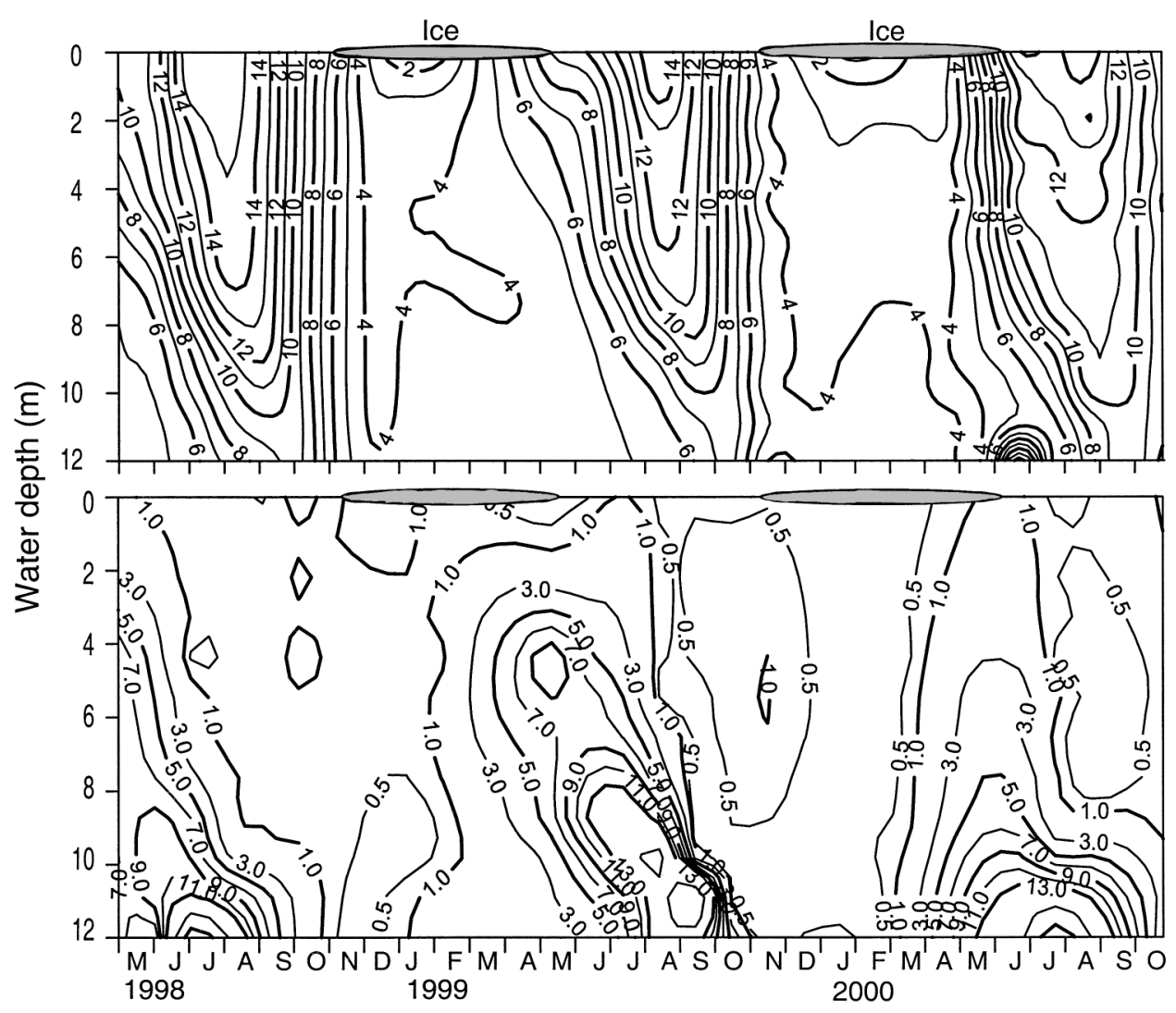

FIG. 1. Temperature $\left({ }^{\circ} \mathrm{C}\right.$; upper panel) and chlorophyll $a$ ( $\mu \mathrm{g} \mathrm{L}^{-1}$; lower panel) isopleths from May 1998 to October 2000 in the Oberer Arosasee, Switzerland (modified from Winder et al. [2003c]).

even in systems with deep-water food maxima. Recently, Lampert et al. (2003) showed in a large mesocosm experiment with a deep-food maximum that, in the absence of predation, Daphnia allocate their time spent in surface and deep-water layers according to the temperature gradient.

These results show that the behavioral response of zooplankton to deep-water algal maxima in the presence of mortality risks in surface waters remains poorly understood. Oligotrophic lakes and mountain lakes often experience deep-water algal maxima (Tilzer 1973, Pilati and Wurtsbaugh 2003) and are therefore suitable environments to answer questions concerning tradeoffs between food and temperature in the presence of fish predation or damaging ultraviolet radiation (UVR). In these lakes, subsurface algal maxima are attributed to high nutrient availability, reduced grazing, and reduced harmful UVR in deep-water layers (Tilzer 1973, Pilati and Wurtsbaugh 2003). The objective of the present study was to investigate the DVM behavior of Daphnia in relation to vertical changes in temperature and food distributions and changing fish biomass in a high-mountain lake with a deep-water food maximum. We combined field observations with in situ enclosures and laboratory mesocosm experiments, and used a fitness model to predict the optimal depth that would maximize fitness for Daphnia under prevailing conditions. We assessed the hypothesis that under safe conditions, Daphnia dwell in depths where growth conditions are maximized, i.e., in subsurface water layers, and move into deeper colder water layers only under high mortality risk.

\section{Materials And Methods}

\section{Field methods}

The study was performed in a dimictic high-mountain lake, Oberer Arosasee, Switzerland, located in the catchment of the River Rhine at an altitude of $1734 \mathrm{~m}$ above sea level. This lake developed a deep-water algae maximum during the summer during the three years of observation (Fig. 1). Obrer Arosasee was annually stocked four times with adult brown trout (Salmo trutta) and charr (Salvelinus alpinus) between June and September. A detailed description of the lake and its plankton and fish community is given elsewhere (Winder et al. $2003 b, c)$. During the open water period, the vertical distribution of Daphnia galeata in the Oberer 
Arosasee was sampled once a week in 1998, every second week in 1999 and monthly in 2000. During the ice cover period, samples were taken twice in 1999 and five times in 2000. In addition, D. galeata was sampled daily during three or four days before and after fish stocking in 1998 and 1999 (for a total of seven or eight observations per event). Samples were taken at midday (1100-1400 hours) and midnight (2300-0100 hours) from three stations around the deepest part of the lake at $2.5-\mathrm{m}$ intervals from 0 to $12.5 \mathrm{~m}$ depth using a duoclosing net (Bürgi 1983). A total of $300 \mathrm{~L}$ per depth stratum was sampled. Samples per depth stratum were pooled, concentrated, and preserved in $90 \%$ ethanol. On each sampling date, temperature was measured at 1-m intervals; chlorophyll $a$ and particulate organic carbon (POC) were measured at six depths (2.5-m intervals) in 1998 and at 12 depths (1-m intervals) in $1999 / 2000$ by the method of Murray et al. (1986) and Uehlinger et al. (1984). Secchi depth was estimated on every sample date.

From every depth stratum, at least 100 D. galeata individuals per development stage (i.e., adult female, juvenile) were counted, or all if fewer individuals were available. Few individuals were found during daytime in the surface water layer and nighttime in the deepwater layer, as well as during winter and early spring when overall density was low (i.e., in total $30 \%$ of the samples in juveniles and $56 \%$ in adults). Mean depth of D. galeata was determined on each sampling date by multiplying the density of individuals per stratum by the average depth of that stratum. These values were summed and divided by the total number of individuals counted in all strata.

We used a model to calculate the expected fitness in the water column of Oberer Arosasee according to the ambient temperature and food (POC) expressed as somatic growth rate. It has been shown that growth rate is a good predictor of instantaneous rate of population growth (Lampert and Trubetskova 1996). Growth rate was estimated from a life-history experiment with $D$. galeata raised on natural seston from different depths of the lake at constant temperature (Winder et al. 2003a) and corrected for lake temperature and lake oxygen concentration (see the Appendix for more details).

\section{Enclosure experiment}

To investigate the influence of fish kairomones on DVM of D. galeata in the lake, we conducted an enclosure experiment. We installed six polyethylene tubes (1 $\mathrm{m}$ diameter, $10 \mathrm{~m}$ deep, $7850 \mathrm{~L}$ volume) in the lake in August 2000. The tubes were open at the surface and closed with a net ( $40 \mathrm{~mm}$ mesh) at the bottom to exclude fish. The bottom of the tubes was below the thermocline, hence reducing water exchange. During installation, the tubes were slowly lowered into the lake, thereby enclosing the natural plankton community. Three replicate enclosures, with and without fish, were installed in a randomized block design. In the three fish replicates, fish presence was manipulated by enclosing four juvenile brown trout (Salmo trutta; $\sim 70$ $\mathrm{mm}$ total length) in cages placed at 2, 6, and $8 \mathrm{~m}$ depths (12 fish per enclosure in total). The enclosures remained in situ from 14 August to 30 August; the experiment was ended when periphyton on the walls of the enclosures began to cause visible shading. Enclosures and the lake were sampled for zooplankton abundance at 5-d intervals with a 5-L Schindler trap at 1$\mathrm{m}$ intervals from the surface to $10 \mathrm{~m}$ depth. POC was measured at 2-m interval and temperature and oxygen was recorded on days 2, 4, and 11. Irradiation spectra were measured using a Macam SC104/B-Cos spectroradiometer for UV-B and UV-A radiation (Macam, Livingston, Scotland) and a spherical quantum sensor LI 193 (Li-Cor, Lincoln, Nebraska, USA) for photosynthetic active radiation (PAR).

\section{Plankton tower experiment}

To understand the role that fish-mediated cues play in determining the vertical distribution of this $\mathrm{D}$. galeata population under the lake's food and temperature vertical distribution, we conducted a large-scale experiment in the two plankton towers at the Max Planck Institute in Plön, Germany (11.2 m high, $0.86 \mathrm{~m}$ diameter; Lampert and Loose 1992) under long daylight conditions (16 h light: $8 \mathrm{~h}$ dark). The summer conditions in the Oberer Arosasee were mimicked in the two towers, especially the deep-water chlorophyll maximum and weak temperature gradient. The food maximum was established at 6-11 $\mathrm{m}$ depth by adding the unicellular alga Scenedesmus obliquus daily into the hypolimnion to a final concentration of $0.8 \mathrm{mg} \mathrm{C} / \mathrm{L}$. Both towers were stocked with a mixed $D$. galeata population from the Oberer Arosasee consisting of 12 clones that were isolated from the lake in spring 2001 and grown as clonal populations in big containers in the laboratory.

Daphnia galeata were acclimated to the experimental temperature, light, and food conditions for $10 \mathrm{~d}$ before sampling started. During this time, densities of D. galeata increased. From day 1 to day 11, both towers received the same treatment, i.e., fish absent. Thereafter (day 12-16), a fish treatment was applied to tower 1 by enclosing two individuals of Leucaspius delineatus (Cyprinidae; $~ 80 \mathrm{~mm}$ total length) in each of two cages, one placed at 1.5 and one at $4 \mathrm{~m}$ depth. From day 17-21, the fish were moved into the cages of tower 2 . Zooplankton samples were taken $10 \mathrm{~h}$ after initiation of daytime conditions and $3 \mathrm{~h}$ after initiation of nighttime conditions ( $n=4$ per treatment). Daphnia were collected simultaneously in both towers using pumps (60 L at each depth) and flow-through traps (Lampert and Loose 1992) at 11 depths $(0.6,2,3,4.5,5,5.5,6$, $7,8,9$, and $10 \mathrm{~m})$. At each depth, at least $100 \mathrm{D}$. galeata individuals per stage (i.e., adult female, juvenile) were counted (if available). 


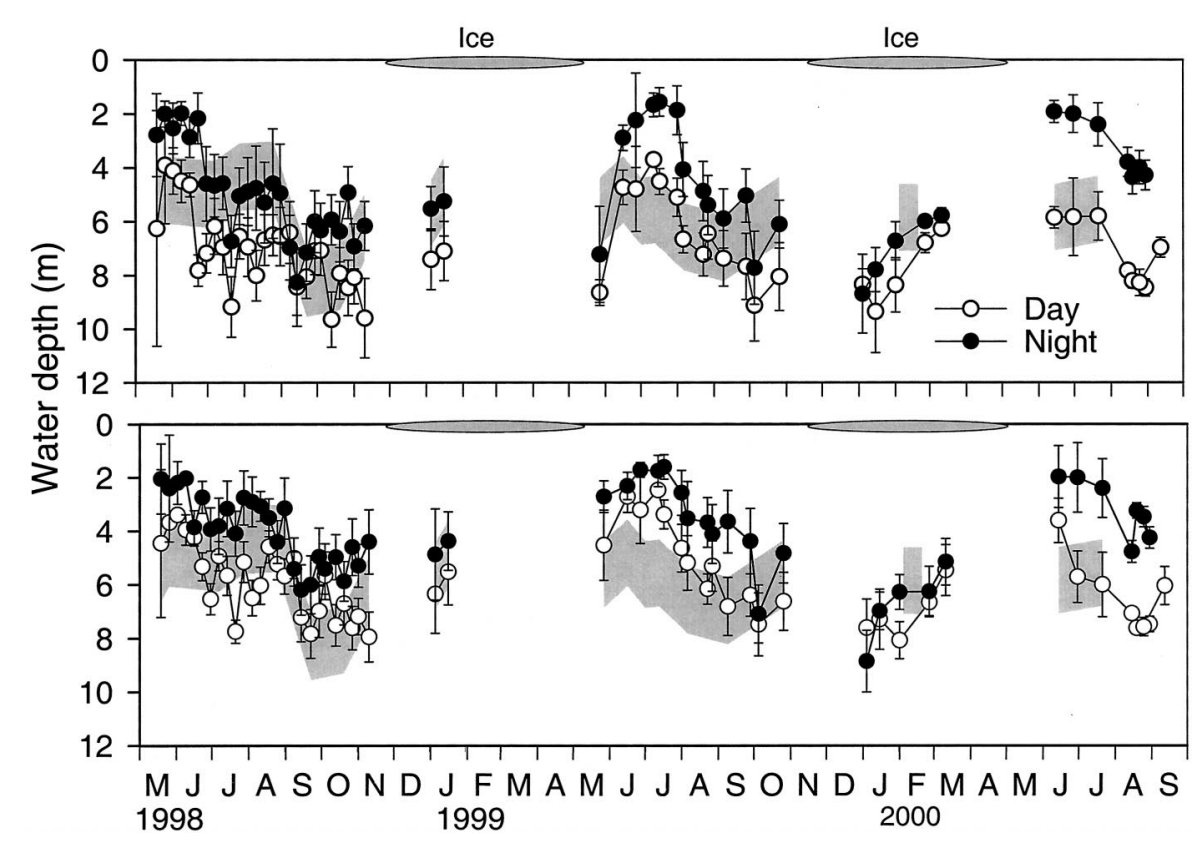

FIG. 2. Mean day (open circles) and night (filled circles) depths of adult female (upper panel) and juvenile (lower panel) Daphnia galeata from May 1998 to September 2000 in the Oberer Arosasee. Error bars indicate 95\% CL. Gray-shaded areas indicate depths with highest expected relative fitness based on juvenile growth rates estimated from particulate organic carbon and temperature measurements in the water column (see Appendix for further details).

After $31 \mathrm{~d}$, part of the water was removed from the bottom of both towers (the lower $2 \mathrm{~m}$ ) and refilled at the top to lower the depth of the food maximum. A new food maximum was established at $8-11 \mathrm{~m}$ with daily replenishments. After $2 \mathrm{~d}$, the thermocline was established again and the vertical distribution of D. galeata (day and night) was determined for another $3 \mathrm{~d}$ with fish treatment in tower 1 and no fish in tower 2 .

\section{Statistical analysis}

In the Oberer Arosasee, differences in the mean depth of D. galeata distribution before and after fish stocking events were analyzed using one-way analysis of variance (ANOVA). To estimate the association between mean D. galeata depths and environmental variables (i.e., Secchi transparency, temperature, food) a first-order autocorrelation was taken into account (Bence 1995). In the enclosure and tower experiments, the vertical percentage distributions of daily measurements were analyzed using principal components analyses (PCA) based on the sample covariance matrix according to Lampert et al. (2003). Following the PCA, significant differences between treatments were detected by using ANOVA on the principal component scores. We chose enough principal components to account for most of the variation in the data (about 95\% of the total). We tested main effects and interactions of fish (present or absent), time (day or night), and food (high concentrations between 5.5 and $11 \mathrm{~m}$ and be- tween 8 and $11 \mathrm{~m}$ ) on the principal components, representing the main aspect of $D$. galeata vertical distribution (Lampert et al. 2003).

\section{RESULTS}

\section{Vertical distribution patterns in the lake}

During the summer months a weak temperature gradient developed in the lake with a mean temperature of $14^{\circ} \mathrm{C}$ in the upper water layers and of $7^{\circ} \mathrm{C}$ in the deep-water layers (Fig. 1). Between ice breakup and autumn turnover, chlorophyll $a$ concentrations were always higher in deeper water layers and the gradient between upper and lower strata increased with month (Fig. 1). Juveniles and adults of D. galeata performed a daily migration throughout most of the 3-yr sampling period (Fig. 2), where maximum migration amplitudes of adults and juveniles were 5.7 and $4.4 \mathrm{~m}$, respectively. The distribution patterns indicate a seasonal trend with increasing mean day and night depths towards autumn for both adult and juvenile $D$. galeata. We found strong positive linear correlations with the mean daytime depths of adult and juvenile D. galeata and Secchi disc transparency, thermocline depth and depth of chlorophyll $a$ increase (Fig. 3). Mean day depths increased with increasing Secchi depth, as did mean daytime and nighttime depths with thermocline depths and increasing depth with chlorophyll $a$ increase. The observed migration pattern of $D$. galeata closely corresponded with the expected distribution 

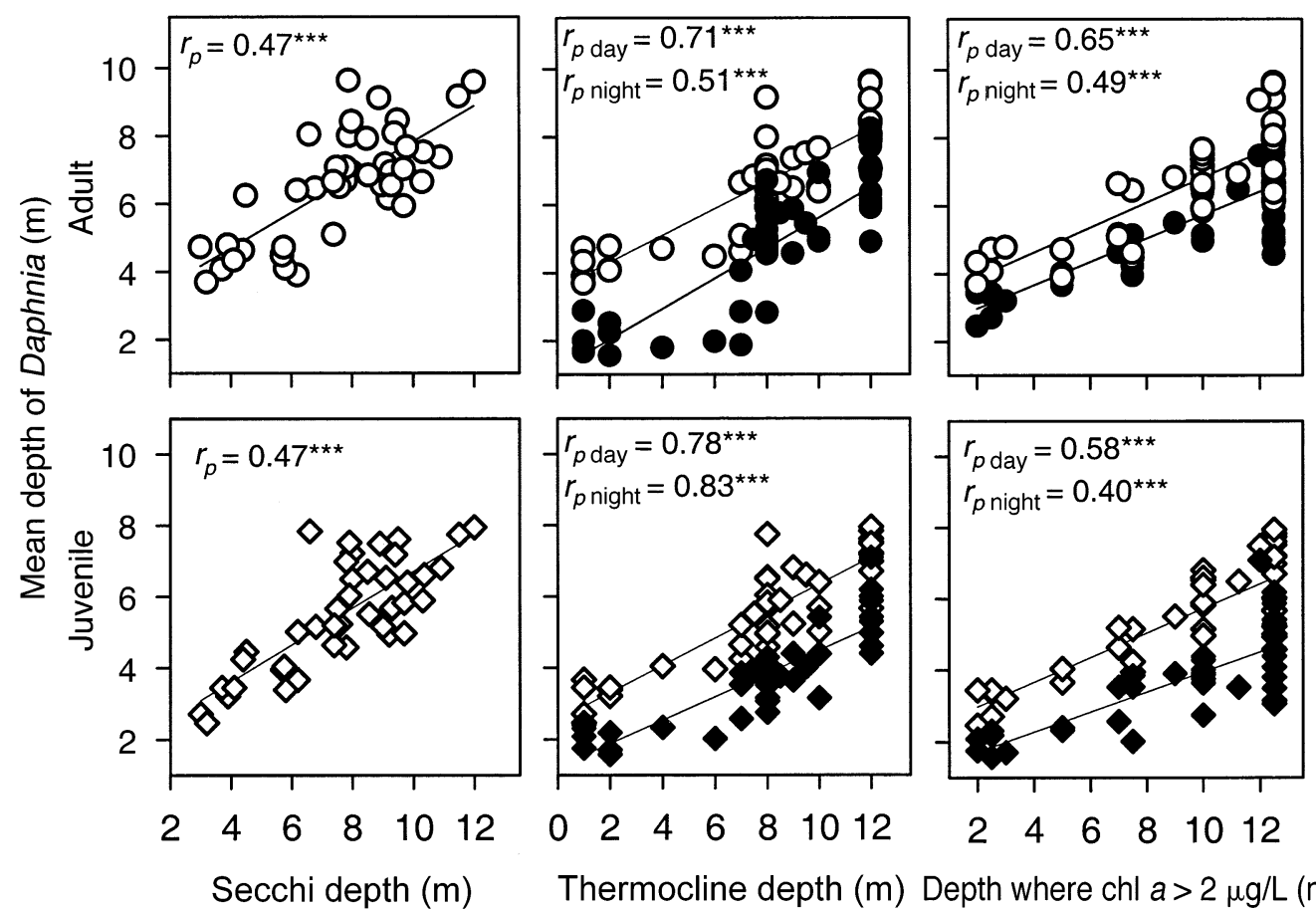

$2 \quad 4 \quad 6 \quad 8 \quad 10 \quad 12$

Secchi depth $(m)$

Thermocline depth (m) Depth where chl $a>2 \mu \mathrm{g} / \mathrm{L}(\mathrm{m})$

FIG. 3. Regression of mean depths of adult female (top panels) and juvenile (bottom panels) Daphnia galeata during the day (open symbols) and night (filled symbols) on environmental independent variables (left panels, light; middle panels, temperature; right panels, food). Light is measured as Secchi depth transparency (m); thermocline depth is the depth of $>1{ }^{\circ} \mathrm{C}$ temperature difference within a $1-\mathrm{m}$ interval; and depth of food increase is the depth where chlorophyll $a>2 \mu \mathrm{g} / \mathrm{L}$. The plots show weekly values from 1998 and biweekly values from 1999 in the Oberer Arosasee, Switzerland, during the icefree period. The partial coefficient of determination is $r_{p}$.

*** $P<0.001$.

based on our calculation of maximal fitness (Fig. 2, gray shaded area). The annual fish stocking did not affect the vertical distribution of $D$. galeata. Before and after the fish stocking, mean day depths $\left(F_{1,12}=\right.$ $0.005, P=0.94)$ and night depths $\left(F_{1,12}=0.064, P=\right.$ $0.81)$ as well as the migration amplitude $\left(F_{1,12}=0.008\right.$, $P=0.93)$ of adult $D$. galeata were not significantly different (data not shown).

During the enclosure experiment, the vertical temperature profile of the enclosures and the lake were similar; POC concentration in the enclosures was slightly higher than in the lake, except for $10 \mathrm{~m}$, but the pattern did not vary significantly from each other (Fig. 4). Oxygen concentration decreased from the surface to $10 \mathrm{~m}$ depth with values between 8.9 and 2.8 $\mathrm{mg} / \mathrm{L}$ in all enclosures and between 11.0 and $1.4 \mathrm{mg} /$ $\mathrm{L}$ in the lake. Average 1\% attenuation depth of PAR in the lake was $7.5 \mathrm{~m}$ and in the enclosures $4.5 \mathrm{~m}$ during the experiment. Average 1\% attenuation depth of UV$A$ in the lake was $2.5 \mathrm{~m}$ and of UV-B was $4 \mathrm{~m}$. We found no difference in the vertical distribution of adult $D$. galeata between enclosures with and without fish $\left(F_{11,34}=0.35, P=0.95\right)$, and the pattern did not differ from the distribution found in the lake (Fig. 4). Average mean day depths in all enclosures were $\sim 6.8 \mathrm{~m}$ and at night $D$. galeata were evenly distributed throughout the water column with mean depths of $\sim 5 \mathrm{~m}$. Time (day, night) significantly affected the vertical distribution pattern in the enclosure $\left(F_{11,34}=16.81, P<\right.$ 0.001). In the lake, adult $D$. galeata had a pronounced daily vertical migration $\left(F_{2,4}=175.6, P=<0.001\right.$; Fig. 4), with a mean day depth of $8.2 \mathrm{~m}$ and a mean night depth of $4.1 \mathrm{~m}$, and thus a slightly higher migration amplitude than in the enclosures. Temperatures were around $11^{\circ} \mathrm{C}$ and $13^{\circ} \mathrm{C}$ at the mean day and night depths. Juvenile $D$. galeata did not react to the presence of fish in the enclosures $\left(F_{10,32}=0.399 ; P=0.94\right.$; Fig. 4). However, vertical distribution patterns of juveniles were significantly different between day and night in the enclosures $\left(F_{10,32}=18.99 ; P<0.001\right)$ with a mean day depth of $6.6 \mathrm{~m}$ and a night depth of $4.2 \mathrm{~m}$ (Fig. 4).

\section{Plankton tower experiment}

Most adult $D$. galeata females resided near the thermocline at the edge of increasing food concentration (5-5.5 $\mathrm{m}$ depth) during both day and night in the absence of fish kairomones (Fig. 5). The daytime vertical distribution of adults was significantly influenced by the presence of fish chemicals (Fig. 5, Table 1). Female 

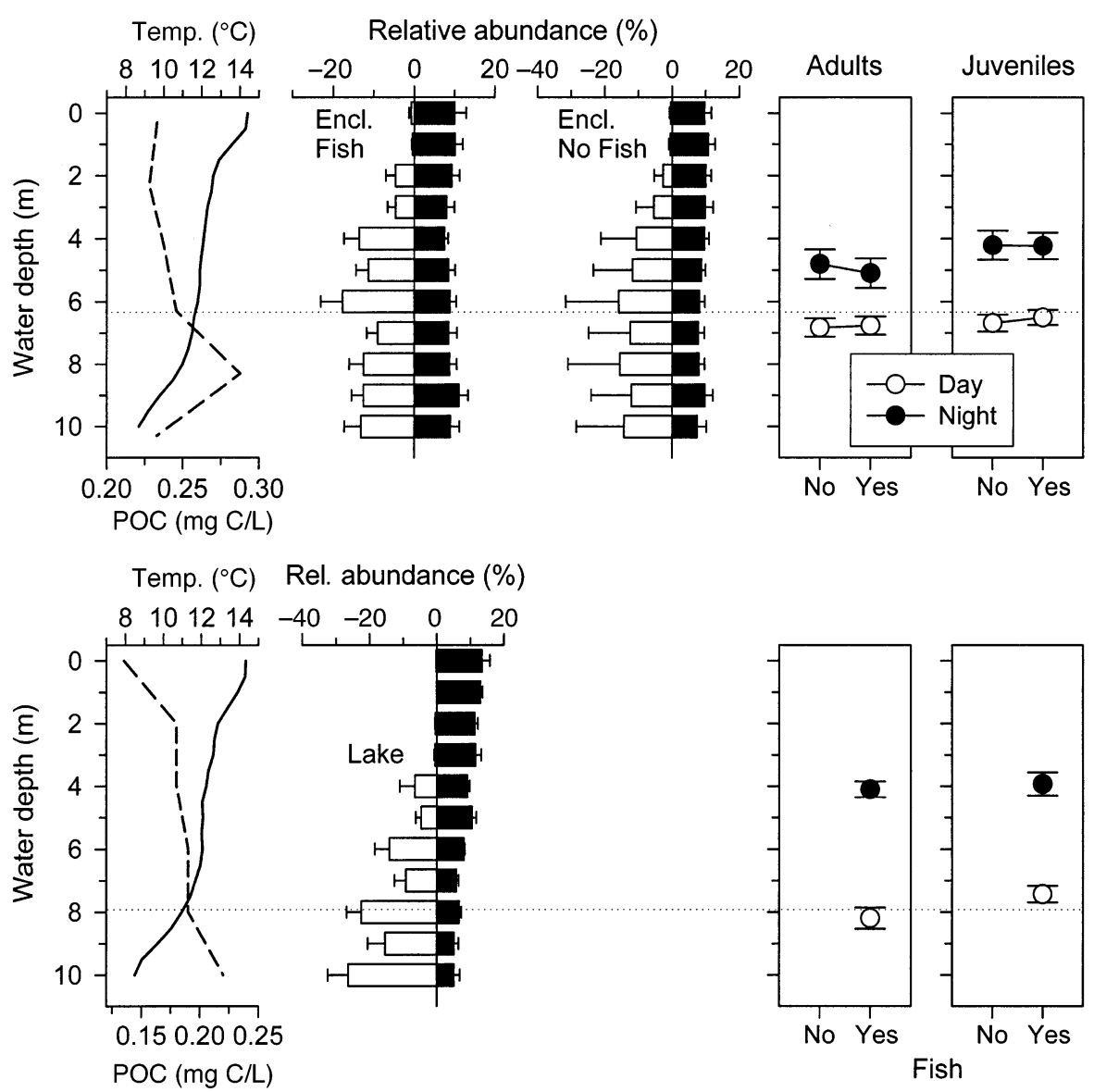

FIG. 4. Average vertical distribution of temperature (solid line), algal carbon (POC; dashed line), and Daphnia galeata in the enclosures (top panels) and the lake (bottom panels). For D. galeata, adult female day (open bars) and night (filled bars) vertical distribution in the enclosures with fish and without fish (error bars indicate $1 \mathrm{SE}$ ), as well as daytime and nighttime mean depth of adults and juveniles in the absence and presence of fish is given in the top panels $(n=4$; error bars indicate $95 \% \mathrm{CL}$ ). In comparison, the vertical algal carbon and temperature distribution as well as D. galeata distribution in the Oberer Arosasee during the enclosure experiment is shown in the bottom panels. The dotted line indicates depth of the thermocline and algal (food) increase.

D. galeata migrated into deeper strata during the day, residing at temperatures between 8 and $10^{\circ} \mathrm{C}$ and returning to the thermocline depth $(5-5.5 \mathrm{~m})$ at night. This migration was reversed after fish were removed from tower 1 and introduced into tower 2. After maximum food concentration was lowered to between 9 and $11 \mathrm{~m}$, the main part of the adult population in the fish treatment followed the food and stayed at $8 \mathrm{~m}$ depth where temperature was $\sim 8^{\circ} \mathrm{C}$ (Fig. 5, Table 1). At night, some D. galeata moved upwards and $\sim 25 \%$ remained at their day depth. A smaller part of the population in the nonfish treatment followed the food downwards and remained there day and night. In contrast, juveniles did not respond to fish chemicals or food by changing their vertical positions in the towers (Fig. 5, Table 1). For adult females, the ANOVA indicated that all three variables (time, food, fish) are significant factors and that there are significant interactions between these factors, whereas, in juveniles, none of these factors were sig- nificant and there were no significant interactions (Table 1).

\section{Discussion}

In systems with deep-water food maxima, zooplankton are faced with a trade-off between low temperature and high feeding opportunity in the deep-water refuge and higher temperatures but low feeding opportunity in the risky surface habitat. We found that part of the Daphnia galeata population migrated upwards at night even when food concentrations were higher in the deepwater layers compared to surface waters, suggesting that factors other than food promote the upward migration. This DVM behavior was observed both in juveniles and in adults throughout most of the year during all three years of the study in the high-mountain Oberer Arosasee (Fig. 2). There is a seasonal trend with increasing mean $D$. galeata depth, going from $\sim 4 \mathrm{~m}$ in June to $\sim 8 \mathrm{~m}$ in October. The observed seasonal trend 

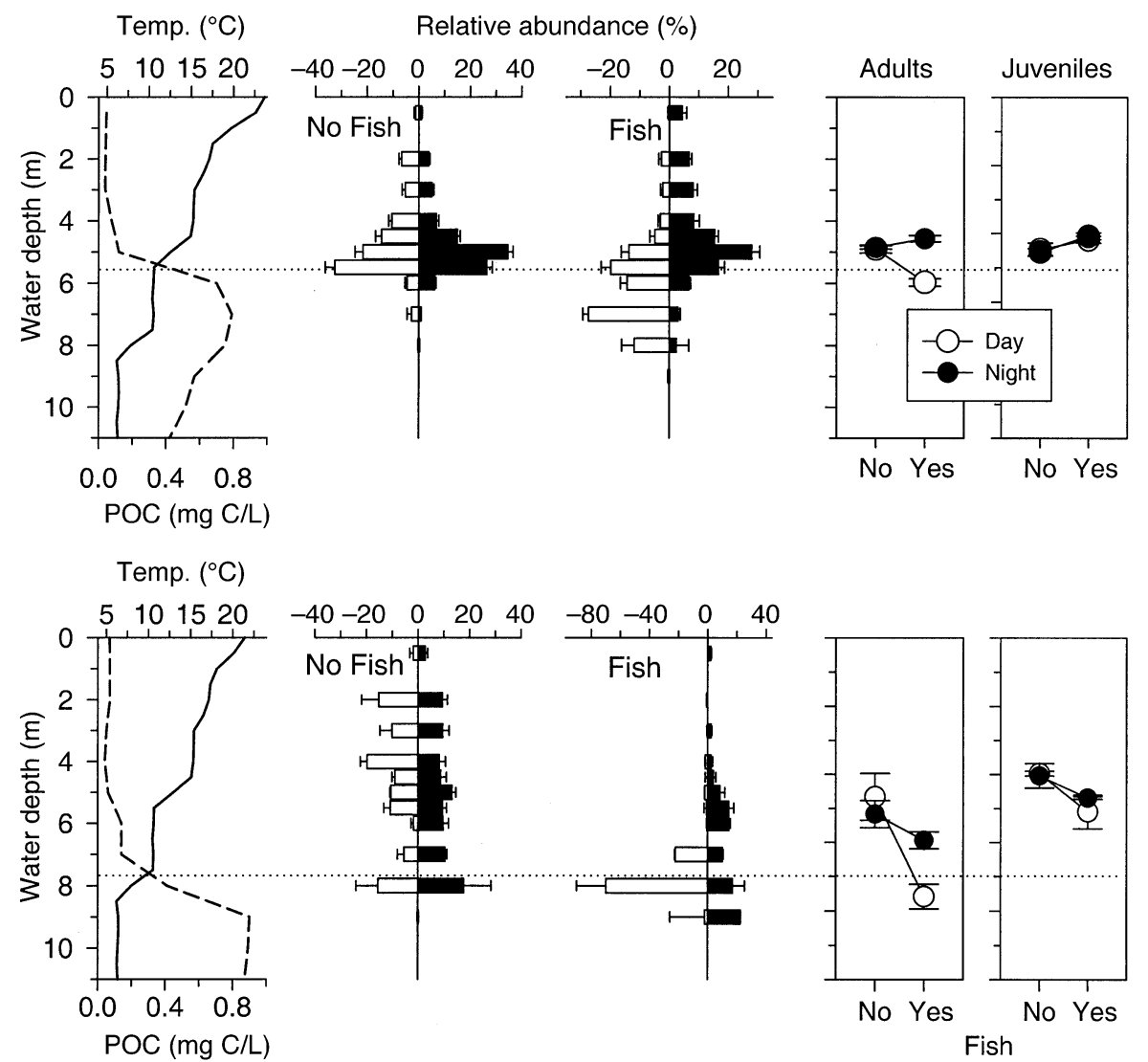

FIG. 5. Mean values of algal carbon $(\mathrm{mg} \mathrm{C} / \mathrm{L})$ and temperature distribution in both plankton towers, mean vertical distribution of adult Daphnia galeata during day (open bars) and night (filled bars; error bars indicate 1 SE), as well as adult females and juveniles daytime and nighttime mean depth in the absence and presence of fish (error bars indicate $95 \% \mathrm{CL}$ ). Top panels show food maxima in towers below $5.5 \mathrm{~m}(n=8$ per treatment and time); bottom panels show food maxima in towers below $8 \mathrm{~m}(n=3$ per treatment and time). The dotted line indicates depth of the thermocline and algal (food) increase.

in D. galeata vertical distribution is highly correlated with the seasonal vertical pattern of temperature, food, and Secchi depth (Fig. 3). During all years and seasons, there was a relatively constant migration amplitude of $\sim 2 \mathrm{~m}$ in adults and $1.5 \mathrm{~m}$ in juveniles. The combination of a deep-water food maximum, and high mortality risk from visual predating fish (De Meester et al. 1995) and
UVR (Winder and Spaak 2002) exposure in the surface waters should promote deeper $D$. galeata distributions during the day, whereas temperature is the only factor that should promote residence in the surface waters. Of these four causal factors, only fish predation and UVR should result in a diel migration pattern of $D$. galeata in the Oberer Arosasee. The fact that the mi-

TABlE 1. Results of three-way ANOVAs to test for the effect of time (day, night), fish factor (yes, no), food (depth of food maxima; high concentration between 5.5 and $11 \mathrm{~m}$ and between 8 and $11 \mathrm{~m}$ depth), and their interactions on the factor scores resulting from PCA analysis from the daily vertical distribution of adult and juvenile Daphnia galeata in the tower experiment.

\begin{tabular}{|c|c|c|c|c|c|c|c|c|}
\hline \multirow[b]{2}{*}{ Factor } & \multicolumn{4}{|c|}{ Adults } & \multicolumn{4}{|c|}{ Juveniles } \\
\hline & $\mathrm{df}$ & MS & $\mathrm{F}$ & $P$ & $\mathrm{df}$ & MS & $\mathrm{F}$ & $P$ \\
\hline Time $(\mathrm{T})$ & 1 & 4.89 & 15.31 & $<0.001$ & 1 & 0.48 & 0.53 & 0.47 \\
\hline Fish factor (Ff) & 1 & 7.04 & 22.03 & $<0.001$ & 1 & 0.25 & 0.28 & 0.59 \\
\hline Food $(\mathrm{F})$ & 1 & 38.44 & 120.29 & $<0.001$ & 1 & 1.64 & 1.8 & 0.18 \\
\hline $\mathrm{T} \times \mathrm{Ff}$ & 1 & 4.37 & 13.69 & $<0.001$ & 1 & 0.03 & 0.03 & 0.86 \\
\hline $\mathrm{T} \times \mathrm{F}$ & 1 & 1.55 & 4.84 & 0.031 & 1 & 1.21 & 1.32 & 0.25 \\
\hline $\mathrm{Ff} \times \mathrm{F}$ & 1 & 4.05 & 12.69 & $<0.001$ & 1 & 2.79 & 3.06 & 0.08 \\
\hline $\mathrm{T} \times \mathrm{Ff} \times \mathrm{F}$ & 1 & 3.55 & 11.11 & 0.001 & 1 & 0.30 & 0.33 & 0.57 \\
\hline Error & 73 & 0.32 & & & 73 & 0.91 & & \\
\hline
\end{tabular}


gration pattern of $D$. galeata in the lake is synchronized with crepuscular periods, i.e., with dawn and dusk, suggests that these light-dependent mortality factors are involved in determining their vertical diel distribution.

In the Oberer Arosasee, D. galeata did not respond to changing fish biomass either after fish stocking or in the enclosure experiment (Fig. 4). The lack of response by $D$. galeata to changes in stocked fish biomass may result from kairomone concentrations in the lake above a threshold such that the stimulus was constant. The $D$. galeata population might respond very strongly to fish kairomones in the sense that maximal response is already observed at very low concentrations (but see Loose 1993). However, the same D. galeata population showed an induced response to fish kairomones in the tower experiment, where we mimicked summer conditions of the lake. In absence of fish kairomones, the D. galeata population remained around the thermocline, where food concentration was high, both during day and night (Fig. 5); however, D. galeata migrated deeper into cold habitats during the day in the presence of fish kairomones. Exchanging the fish between the towers reversed and induced this response rapidly (within a day), suggesting that $D$. galeata individuals are able to quickly modify their behavior in response to predation risk. In addition, the migration response in the lake to changing vertical food distribution could be simulated in the towers. During the day, adult $D$. galeata migrated into deeper, colder, water strata and returned at night to the depth of thermocline in the towers, or were spread over the whole water column in the lake. When the maximum food level was lowered to 8 and $11 \mathrm{~m}$ depth in the towers (Fig. 5), adult $D$. galeata migrated into deeper water layers following the food. Especially in the presence of fish, all individuals stayed around the depth where food was increasing and distribute over the water column in the absence of fishmediated cues. Our ANOVA result showed that not only the single factors were significant, but also the interaction between the fish and food factors (Table 1), indicating that the response of food depends upon the presence of fish and vice versa.

The similar behavior of adult D. galeata in the tower in the presence of fish to the behavior of the D. galeata in the lake is striking (Figs. 4 and 5), especially during the day. The presence of fish induced a vertical migration for adult females of $\sim 2 \mathrm{~m}$ in the towers, which is of the same amplitude as adults in the lake enclosures. With increasing depth of food maxima, the migration amplitude was higher in the lake than in the plankton towers (Figs. 4 and 5). This difference may be related to the fact that $D$. galeata has a temperature optimum around $15^{\circ} \mathrm{C}$ (Gillooly and Dodson 2000) and thus have to migrate into shallower depths in the lake than in the plankton towers, because plankton towers had warmer surface temperatures.

In comparison to adults, the migration behavior of juveniles was different between lake and plankton tow- ers. In the lake, juvenile $D$. galeata showed a migration behavior but not in the plankton towers (Fig. 5). Since the same clones are involved, the contrasting behavior in the lake and the tower experiments suggest that there must be a difference in a proximate environmental factor between the lake and towers. The most obvious possibility could be the difference in UVR (Hutchinson 1967, Leech and Williamson 2001, Rhode et al. 2001). In the towers, UVR is absent (Lampert and Loose 1992), whereas, in the Oberer Arosasee, the hazardous effect of UVR on D. galeata is especially pronounced in the surface during summer (Winder and Spaak 2002), where $D$. galeata do not reach maturity when exposed to full solar radiation. Therefore, only subsurface strata remain an effective refuge for small and large zooplankton during daylight in this high-mountain lake, where UVR is mostly absorbed in the upper $2 \mathrm{~m}$ (Winder and Spaak 2002). In addition, all stages of the copepod species (Eudiaptomus gracilis, Cyclops abyssorum) present in this lake also avoided surface waters during daytime (Winder et al. 2003c). UVR probably does determine the timing of migration, i.e., its synchronization with dawn and dusk. However, UVR cannot be the major driving force of vertical migration of adult $D$. galeata, because the mean depths and migration amplitude in adults are higher than in juveniles. Therefore, fish kairomones may enhance the migration amplitude in adults in the lake.

An additional cause for the observed diel migration pattern of D. galeata in the lake may be a response to invertebrate predators (Neill 1990). Adult Cyclops species are the only potential invertebrate predators present in this lake. Since this copepod species exhibits a migration behavior similar to $D$. galeata (Winder et al. $2003 c$ ), it can be excluded to influence DVM of $D$. galeata. The avoidance of competitive interactions among coexisting Daphnia individuals by temporal shift in habitat selection (Hu and Tessier 1995, Leibold and Tessier 1997), however, could be a proximate mechanism for the observed nighttime distribution patterns. In the lake, most of the D. galeata reside in deepwater layers during the day, thus total densities may be up to 60 individuals/L (M. Winder, unpublished data). Under low mortality risk (nighttime), D. galeata occur over the whole water column and part of the population resides in deep-water layers, with $D$. galeata densities up to 30 individuals/L. However, it is unclear whether Daphnia density affects their distribution in a patch. Larsson (1997) and Lampert et al. (2003) showed with a horizontal and vertical food gradient, respectively, only weak evidence that Daphnia used population density in choosing their position in the patch. Moreover, Lampert et al. (2003) suggested that Daphnia distribute at night according to the ideal free distribution (IFD) with costs model (Tyler and Gilliam 1995). This model describes the distribution of species in a food gradient associated with environmental costs (e.g., temperature). For zooplankton, this 
distribution model can be tested in lakes with deepwater food maxima, where plankton experience tradeoffs in fecundity and rate of development. We used the combination of the relative food and temperature values in the lake to calculate the relative fitness in a particular depth. Maximum fitness was reached in the mid-water layers (Fig. 2), depending on the vertical food and temperature distribution. In accordance with changing depth of maximum fitness, the mean depth of adult $D$. galeata changed and this species distributes in the optimal depth during day and night, except during nighttime in spring. This result suggests that, in lakes, $D$. galeata distribute according to the IFD with cost model under predator-free conditions. However, in our system, we were not able to account for density effects, which are an important component of the IFD (Fretwell and Lucas 1970).

In spring or early summer, D. galeata migrated at night outside the optimal fitness range with low food concentration but high temperature (Fig. 2). Since temperature can accelerate reproductive parameters like age at maturity and brood duration (Orcutt and Porter 1983), the migration into warmer temperature under low predation risk may be an adaptive strategy in this lake with low overall temperatures and short growing seasons. This may be especially important in spring, when overall temperature is low and fecundity is highest (Winder et al. 2003b). Thus, the upward movement of Daphnia at night into surface waters, which are outside the maximum expected fitness range, suggests being an acceleration of growth due to warmer temperatures, but not a feeding gain. Regarding the conflicting hypothesis of zooplankton response to deep-water algal maxima, our study reveals that in these systems adult Daphnia move on a daily basis between habitats that minimize mortality risk and maximize fitness.

\section{ACKNOWLEDGMENTS}

We thank all the people who assisted within the fieldwork. We are grateful to Professor W. Lampert who allowed us to use the plankton towers in Plön and for his comments on the manuscript. Eva Momberger-Geißler, Colleen Jamieson, Kirsten Kessler, and Maren Volquardsen are acknowledged for helpful contributions during the tower experiment. Comments by Wendy Palen, John Havel, and two anonymous reviewers improved the manuscript. Financial support was provided by a grant from the DAAD (Deutscher Akademischer Austauschdienst) and the Swiss Federal Office for Education and Science (No. 97.0040).

\section{Literature Cited}

Bence, J. R. 1995. Analysis of short-time series-correcting for autocorrelation. Ecology 76:628-639.

Bottrell, H. H., A. Duncan, Z. M. Gliwicz, E. Grygierek, A. Herzig, A. Hillbricht-Ilkowska, H. Kurasawa, P. Larsson, and T. Weglenska. 1976. A review of some problems in zooplankton production studies. Norwegian Journal of Zoology 24:419-456.

Bürgi, H. R. 1983. Eine neue Netzgarnitur mit Kipp-Schliessmechanismus für quantitative Zooplanktonfänge in Seen. Schweizerische Zeitschrift für Hydrologie 45:505-507.
Cullen, J. J. 1982. The deep chlorophyll maximum: comparing vertical profiles of chlorophyll $a$. Canadian Journal of Fisheries and Aquatic Sciences 39:791-803.

De Meester, L., L. J. Weider, and R. Tollrian. 1995. Alternative anti-predator defenses and genetic polymorphism in a pelagic predator-prey system. Nature 378:483-485.

Dini, M. L., and S. R. Carpenter. 1992. Fish predators, food availability and diel vertical migration in Daphnia. Journal of Plankton Research 14:359-377.

Fee, E. J. 1976. The vertical and seasonal distribution of chlorophyll in lakes of the Experimental Lakes Areas, northwestern Ontario: implications for primary production estimates. Limnology and Oceanography 21:767-783.

Fretwell, S. D., and H. J. Lucas. 1970. On the territorial behavior and factors influencing habitat distribution in birds. Acta Biotheretica 19:16-36.

Gillooly, J. F., and S. I. Dodson. 2000. Latitudinal patterns in the size distribution and seasonal dynamics of new world, freshwater cladocerans. Limnology and Oceanography $45: 22-30$.

Gliwicz, Z. M., and J. Pijanowska. 1988. Effect of predation and resource depth distribution on vertical migration of zooplankton. Bulletin of Marine Science 43:695-709.

Hu, S. X., and A. J. Tessier. 1995. Seasonal succession and the strength of intra- and interspecific competition in a Daphnia assemblage. Ecology 76:2278-2294.

Hutchinson, G. E. 1967. A treatise on limnology. Volume II: introduction to lake biology and the limnoplankton. John Wiley and Sons, New York, New York, USA.

Lampert, W. 1978. A field study on the dependence of the fecundity of Daphnia species on food concentration. Oecologia 36:363-369.

Lampert, W. 1993. Ultimate causes of diel vertical migration of zooplankton: new evidence for the predator avoidance hypothesis. Archiv für Hydrobiologie, Beiheft Ergebnisse der Limnologie 39:79-88.

Lampert, W., and C. J. Loose. 1992. Plankton towers-bridging the gap between laboratory and field experiments. Archiv für Hydrobiologie 126:53-66.

Lampert, W., E. McCauley, and B. F. J. Manly. 2003. Tradeoffs in the vertical distribution of zooplankton: ideal free distribution with costs? Proceedings of the Royal Society of London Series B, Biological Sciences 270:765-773.

Lampert, W., and I. Trubetskova. 1996. Juvenile growth rate as a measure of fitness in Daphnia. Functional Ecology 10: 631-635.

Larsson, P. 1997. Ideal free distribution in Daphnia? Are daphnids able to consider both the food patch quality and the position of competitors? Hydrobiologia 360:143-152.

Leech, D. M., and C. E. Williamson. 2001. In situ exposure to ultraviolet radiation alters the depth distribution of Daphnia. Limnology and Oceanography 46:416-420.

Leibold, M. A., and A. J. Tessier. 1997. Habitat partitioning by zooplankton and the structure of lake ecosystems. Pages 3-30 in B. Streit, T. Städler, and C. M. Lively, editors. Evolutionary ecology of freshwater animals. Birkhäuser, Basel, Switzerland.

Loose, C. J. 1993. Daphnia diel vertical migration behaviour: response to vertebrate predator abundance. Archiv für Hydrobiologie, Beiheft Ergebnisse der Limnologie 39:29-36.

Loose, C. J., and P. Dawidowicz. 1994. Trade-offs in diel vertical migration by zooplankton: the costs of predator avoidance. Ecology 75:2255-2263.

Murray, A. P., C. F. Gibbs, A. R. Longmore, and D. J. Flett. 1986. Determination of chlorophyll in marine waters: intercomparison of a rapid HPLC method with full HPLC, spectrophotometric and fluorometric methods. Marine Chemistry 19:211-227.

Neill, W. E. 1990. Induced vertical migration in copepods as a defense against invertebrate predation. Nature 345:524525 . 
Orcutt, J. D., and K. G. Porter. 1983. Diel vertical migration by zooplankton: constant and fluctuating temperature effects on life history parameters of Daphnia. Limnology and Oceanography 28:720-730.

Pilati, A., and W. A. Wurtsbaugh. 2003. Importance of zooplankton for the persistence of a deep chlorophyll layer: a limnocorral experiment. Limnology and Oceanography 48: 249-260.

Rhode, S. C., M. Pawlowski, and R. Tollrian. 2001. The impact of ultraviolet radiation on the vertical distribution of zooplankton of the genus Daphnia. Nature 412:69-72.

Tilzer, M. 1973. Diurnal periodicity in the phytoplankton assemblage of a high mountain lake. Limnology and Oceanography 18: $15-30$.

Tyler, J. A., and J. F. Gilliam. 1995. Ideal free distributions of stream fish: a model and test with minnows, Rhinicthys atratulus. Ecology 76:580-592.

Uehlinger, U., P. Bossard, P. Bloesch, H. R. Bürgi, and H. Bührer. 1984. Ecological experiments in limnocorrals: methodological problems and quantification of the epilimnetic phosphorus and carbon cycles. Verhandlungen Internationale Vereinigung für theoretische und angewandte Limnologie 22:163-171.
Vos, M., B. J. G. Flik, J. Vijverberg, J. Ringelberg, and W. M. Mooij. 2002. From inducible defences to population dynamics: modelling refuge use and life history changes in Daphnia. Oikos 99:386-396.

Williamson, C. E., R. W. Sanders, R. E. Moeller, and P. L. Stutzman. 1996. Utilization of subsurface food resources for zooplankton reproduction: implications for diel vertical migration theory. Limnology and Oceanography 41:224233.

Winder, M., M. Boersma, and P. Spaak. 2003a. On the cost of vertical migration: are feeding conditions really worse at deeper depth? Freshwater Biology 48:383-393.

Winder, M., H. R. Bürgi, and P. Spaak. 2003b. Factors regulating zooplankton succession in a high-mountain lake. Freshwater Biology 48:795-809.

Winder, M., and P. Spaak. 2002. Effects of natural UV radiation on the life history of alpine Daphnia. Verhandlungen Internationale Vereinigung für theoretische und angewandte Limnologie 28:355-359.

Winder, M., P. Spaak, and H. R. Buergi. 2003c. Seasonal vertical distribution of phytoplankton and copepods in a high-mountain lake. Archiv für Hydrobiologie 158:197213 .

\section{APPENDIX}

The model for calculating expected Daphnia fitness in the water column is available in ESA's Electronic Data Archive: Ecological Archives E085-058-A1. 